\title{
Effects of four years of exercise, language, and social interventions on Alzheimer discourse
}

\author{
Nidhi Mahendra ${ }^{\mathrm{a}, \mathrm{b}, *}$, Sharon Arkin $^{\mathrm{b}}$ \\ ${ }^{a}$ Department of Communicative Sciences \& Disorders, \\ California State University, Hayward, CA, USA \\ ${ }^{\mathrm{b}}$ Department of Speech \& Hearing Sciences, The University of Arizona, Tucson, AZ, USA
}

Received 15 March 2003; received in revised form 15 May 2003; accepted 15 May 2003

\begin{abstract}
This article describes a comprehensive cognitive-linguistic intervention program for mild to moderate Alzheimer's disease (AD) patients that provided communication skills practice in the context of health-enhancing and esteem-building community-based activities: physical fitness training and supervised volunteer work. The interventions were administered by undergraduate students who completed academic work, received faculty supervision, and earned three credits for one semester of participation. Effects of the interventions on the discourse of four participants who completed all 4 years of the program are reported in detail. The maintained or improved performance on multiple discourse outcome measures provides powerful rationale for making such interventions more widely available and preliminary support for their effectiveness in preserving communicative function. An additional role for speech-language pathologists (SLPs) - as trainers and supervisors of non-professional rehab partners for persons with dementia-is proposed. Learning outcomes: From this article, participants will be able to (1) list specific language tasks that can be used to assess discourse in individuals with AD; (2) identify several cognitive-linguistic interventions appropriate for use with AD patients; and (3) understand how long-term cognitive-linguistic interventions may affect the language performance of individuals with AD.
\end{abstract}

(C) 2003 Elsevier Inc. All rights reserved.

Keywords: Discourse; Dementia; Alzheimer's disease; Interventions

* Corresponding author. Tel.: +1-510-713-1837; fax: +1-510-713-8380.

E-mail address: nidhiaz@hotmail.com (N. Mahendra). 


\section{Introduction}

Individuals with dementia represent the fastest growing clinical population served by speech-language pathologists (SLPs). It is estimated that by the year 2040, approximately 14 million Americans will be afflicted with Alzheimer's disease (AD) or similar dementias (Evans, 1990). The breadth of their training and scope of practice qualifies SLPs to enhance the clinical management of dementia patients through comprehensive assessment of and intervention for cognitive, communicative, and swallowing difficulties. However, despite the training and skills to provide cognitive, communicative, and swallowing assessment and intervention services, most SLPs find dysphagia evaluation and treatment services forming the bulk of their clinical work with dementia patients in long-term care settings.

This has occurred largely because of the insistence by Medicare on the "medical necessity" of services provided by rehabilitation professionals in long-term care settings. Treatment of symptoms such as aspiration risk, weight loss, malnutrition, and dysphagia fit more cleanly under the category of "medically necessary," reimbursable services and thus, they are more frequently requested by physicians and nurses than cognitive and communicative services. Outcomes of dysphagia therapy as compared to those of cognitive-linguistic therapy, are also more tangible (increased body weight, greater percentage of meal consumed, etc.), and easier to document objectively (reduced coughing, diet modification, etc.). Unfortunately, interventions that enhance orientation, improve amount of meaningful communication, improve recall of autobiographical information, decrease frequency of disruptive vocalizations, and improve affect and mood of dementia patients are seldom ordered by physicians.

Finally, the progressive nature of $\mathrm{AD}$ means that treatment outcomes may be limited to maintenance of function, which is discouraging to health care professionals trained to anticipate improvement as a result of their efforts (Clark \& Witte, 1991). The combined effects of these trends in reimbursement practices and provider negativism have greatly limited the role of SLPs in serving dementia patients in many life-enhancing areas. Bayles (2001) urges SLPs to invoke ASHA's Code of Ethics and the OBRA (Omnibus Budget Reconciliation Act, 1987) mandate to focus primarily on the welfare of dementing patients and to offer the highest quality of service so individuals with dementia may function at the highest level possible. Clinicians need to develop new cost-effective ways to deliver a wider range of services in long-term care settings. They also need to stay abreast of empirical evidence about the efficacy and effectiveness of short-term, long-term, direct, and indirect interventions to maintain and/or improve function and quality of life in dementia patients (e.g., Arkin, 2001; Camp, Foss, O'Hanlon, \& Stevens, 1995; Clare et al., 2000; Hopper, 2001; Mahendra, 2001; Moss, Polignano, White, Minichiello, \& Sunderland, 2002, and other articles in this issue). Furthermore, clinicians need to participate in collaborative research efforts to fill gaps in the research concerning non-pharmacological interventions. 
The Elder Rehab program developed at the University of Arizona's Department of Speech \& Hearing Sciences provides a unique model to compensate for the limited amount and duration of direct cognitive-linguistic interventions that Medicare allows SLPs to provide to individuals with AD. As will be shown, it fulfills all of the basic needs of persons with dementia postulated by the BASICS biopsychosocial model (Vickers, 1974, as cited in Ronch, 1987) for dementia environments and interventions: Biological, ADLs, Societal, Interpersonal, Creative, and Symbolic (Appendix A). It offers an easily-replicated system of using students to administer and supervise rehab interventions. It is cost-effective because the students are not paid for providing these services. Rather they pay tuition for this experience and are compensated through the faculty supervision, learning and academic credits they receive. Unlike the overburdened family caregivers of persons with dementia, students tend to be energetic, enthusiastic, optimistic, and free of the "therapeutic nihilism" attributed by Clark (1995) to SLPs and other professionals who deal with dementia. The role played by students could also be filled by paid caregivers, volunteers, and motivated family members. Though this intervention model was developed in an outpatient context, it could be easily adapted to skilled nursing or assisted living facility settings. The SLP can be the catalyst who mobilizes available but untapped human and community resources to deliver language stimulation activities for improving quality of life. In this article, we present a detailed description of the multi-component Elder Rehab program and its activities, and attempt to fill the gap in the literature on the effects of direct, longitudinal interventions on the language and discourse of dementia patients.

\section{Background}

\subsection{Volunteers in Partnership (VIP)}

The Elder Rehab program was an outgrowth of an earlier program-Volunteers in Partnership (Arkin, 1995, 1996). VIP paired 12 individuals with dementia with students who supervised them in 10-weekly, 2-h sessions consisting of volunteer service or other meaningful community activity and including 30-50 min of students administering structured verbal fluency and conversational stimulation. Gains in number of substantive on-topic statements produced on a discourse sample were achieved by 7 of the 12 participants. Eight participants also showed improvement in their ability to describe pictures and to interpret proverbs.

Structuring opportunities for persons with dementia to be of service to others provided them an important opportunity to re-connect to the community and to assume responsibilities that gave definition to their lives. Thus, the program addressed the Societal, Interpersonal, and Creative needs areas mandated by the BASICS model. For a review of the psychosocial benefits of volunteering and 
description of a supervised volunteer service program for early stage dementia patients operated by an adult daycare center in Chicago, see Stansell (2002).

\subsection{Elder Rehab}

The Elder Rehab program, which was the context for the discourse study reported here, added another normalizing and beneficial activity_physical exercise to the interventions offered in the VIP program. Physical exercise sessions took place in a wellness/cardio rehab facility where participants interacted with medical students, doctors, nurses, other hospital employees and patients of the University of Arizona Medical Center. Memory and language stimulation activities were administered during workouts on a treadmill, stationary bicycle, and during rest periods. The physical fitness activities address the Biological needs area in the BASICS model by increasing cardiovascular fitness and strength and the ADL area by maintaining or increasing ambulation, balance, and the ability to bend, lift, rise from a chair, lower oneself into a car, dress, and carry out household chores.

\section{Methods}

\subsection{Study participants}

Twenty-four mild to moderate stage AD patients, aged 54-86 years at entry, participated for 1-4 years in the Elder Rehab program between September 1997 and June 2001. Their baseline Mini-Mental State Exam (MMSE) (Folstein, Fosletin, \& McHugh, 1975) scores ranged from 15 to 29 . The four who completed all 4 years and whose discourse performance is reported here were one man, aged 59 years at entry, and three women in their eighties. See Table 1 for their demographic characteristics and baseline scores on the MMSE and the Arizona Battery for Communication Disorders of Dementia (ABCD; Bayles \& Tomoeda, 1991). Independent sample $t$-tests were conducted to compare their baseline

Table 1

Participant demographic characteristics

\begin{tabular}{llllllll}
\hline Subject & Sex & Age $^{\mathrm{a}}$ & MMSE $^{\mathrm{b}}$ & ABCD $^{\mathrm{c}}$ & $\begin{array}{l}\text { Education } \\
\text { (in years) }\end{array}$ & Residence & $\begin{array}{l}\text { Primary } \\
\text { occupation }\end{array}$ \\
\hline S1 & M & 59 & 23 & 20.6 & 12 & With spouse & Electrician \\
S2 & F & 83 & 17 & 16.7 & 14 & Assisted living & Homemaker \\
S3 & F & 84 & 26 & 18.9 & 12 & Group home & School bus driver \\
S4 & F & 86 & 29 & 20.9 & 12 & Home alone & Mobile home \\
& & & & & & & park owner \\
\hline
\end{tabular}

\footnotetext{
${ }^{\text {a }}$ Age at baseline.

${ }^{\mathrm{b}}$ Mini-Mental State Exam score at baseline.

${ }^{c}$ Arizona Battery for Communication Disorders of Dementia score at baseline.
} 
characteristics to the other 20 participants. No significant differences were found between the two groups in age, years of education, mean MMSE and ABCD scores, stage of dementia as measured by the Clinical Dementia Rating (CDR) (Berg, 1988), or number of comorbidities.

Participants were diagnosed, tested, and enrolled according to criteria, procedures, and instruments used by the Consortium to Establish a Registry for Alzheimer's Disease (CERAD; Morris et al., 1989). All met the criteria for a clinical diagnosis of Alzheimer's disease as established by the National Institute of Neurological and Communicative Disorders and Stroke/Alzheimer's Disease and Related Disorders Association (NINCDS/ADRDA; McKhann et al., 1984). All participants passed a speech discrimination screening administered as part of the ABCD.

\subsection{Student Rehab partners}

Undergraduate student participants were recruited from many different departments in response to mass emails sent to honor students, pre-health science majors, and other likely groups. Eighty percent of the participants were females. Students were accepted on a first-come, first-served basis; the only requirements being access to a motor vehicle, a current driver's license, and auto insurance. The University's Risk Management department provided liability insurance coverage secondary to the student's own insurance. In 4 years of student-provided transportation and supervision of study participants, no accidents or injuries occurred during program activities. The students earned three independent study credits for one semester of participation. Their responsibilities included driving the patient to and from program activities in their (the student's) personal vehicle; supervising one exercise plus memory and language stimulation session, and one community activity plus walking session per week for 10 weeks. Additionally, each student attended six, 2-h seminars related to dementia, exercise, and aging and received group and individual training and supervision in the administration and recording of intervention activities.

\subsection{Cognitive-linguistic assessment}

Study participants were assessed at enrollment and after every two semesters of intervention with a battery of standardized cognitive and language tests, plus the battery of discourse measures created for this study. The standardized tests used were the CERAD neuropsychological battery which includes the MMSE, a 15-item short version of the Boston Naming test (BNT; Kaplan, Goodglass, \& Weintraub, 1983), and a timed category fluency test; the ABCD; and the WAIS-R Similarities and Comprehension sub-tests (Wechsler, 1981). Study participants were also assessed by a CERAD-certified clinician according to the CDR, a structured interview protocol used by the CERAD to establish the stage of dementia (Morris et al., 1989). 


\subsection{Discourse outcome measures}

The discourse battery used to monitor language performance of Elder Rehab participants had three parts: (a) eight stimulus prompts or questions on a variety of topics relevant to mature adults, (b) a five-item proverb interpretation (PI) task, and (c) a picture description task. The tasks were selected to elicit the five different discourse types described by Shadden (1995). (For a detailed discussion of the rationale for each component, see Arkin \& Mahendra, 2001a.)

(A) Eight stimulus prompts:

1. Tell me what you know about John F. Kennedy and his family.

2. Tell me what you know about Alzheimer's disease.

3. This was used to assess insight as well as discourse (Arkin \& Mahendra, 2001b, in press).

4. Tell me about your daily activities, the things you do every day.

5. Tell me about the things you do once in a while, not every day. Prompts 3 and 4 assessed participant discourse and level of awareness about their current life.

6. Tell me the childhood thoughts and memories the word "play" reminds you of.

7. Tell me the adult thoughts and memories the word "play" reminds you of.

8. How would you go about planning a picnic for your family or some friends?

9. Supposing the 13-year-old daughter of a neighbor told you she was pregnant, but was afraid to tell her mother. What would you do? What are some of the ways the family could handle that situation? The second part of Prompt 8 was designed to see how many solutions respondents could suggest for the presented situation.

Responses to these prompts were audio and videotaped, and transcribed by students. Transcripts were demarcated into utterances and coded, according to procedures previously described (Arkin \& Mahendra, 2001a). Responses to each prompt were scored in terms of: (a) total utterances; (b) topic comments (complete, content-filled, non-ambiguous, "non-empty" statements relevant to the topic under discussion); (c) neutral utterances; (d) negative utterances (e.g., confabulations, repetitions, incomplete thoughts, meaning unclear statements); (e) total nouns; (f) different nouns; and (g) vague nouns (e.g., stuff, thing). Ratios were computed to determine percentage of positive and negative utterances and different noun types relative to total utterances. High interand intra-scorer agreement $(\geq 80 \%)$ on utterance demarcation, classification, and noun counts was established after extensive training and discussion on instances of disagreement (see Arkin \& Mahendra, 2001a for details). 
(B) Five-item proverb interpretation task: The five-item proverb interpretation task was adapted from Delis, Kramer, and Kaplan (1984). The five proverb stimuli used were:

1. They see eye to eye.

2. Too many cooks spoil the broth.

3. Rome wasn't built in a day.

4. Don't count your chickens before they hatch.

5. You can't tell a book by its cover.

Participant responses were scored along a seven-point concretenessabstractness continuum (Chapman et al., 1997-Appendix B) with 6 being a complete abstract response and 0 being an incorrect or no response. The highest possible score on the test was 30 (5 items $\times 6$ points). To ensure reliability of scoring, baseline and first year postintervention transcripts were scored by Chapman and colleagues, using their guidelines (Chapman et al., 1997). At the end of the first year, the second author scored all patient responses, following Chapman's guidelines and consulting with her on questionable responses. Intra-scorer agreement was obtained after re-scoring $25 \%$ of participant transcripts and determining item-by-item reliability to be $75 \%$.

(C) Grocery store picture description: This task is from the Aphasia Diagnostic Profiles (ADP; Helm-Estabrooks, 1992). Participants were asked to describe the picture in as much detail as possible and when they stopped, they were encouraged to provide more information by use of general prompts such as "Is there anything else you can tell me about this picture?" Descriptive discourse elicited was scored according to the guidelines and list of acceptable sample information units provided in the ADP manual. Prepositional phrases, multiple verb forms, as well as pronouns relating to a new topic (personal communication, Helm-Estabrooks, 1997) were also given credit.

\section{Interventions}

Student participants administered one 2-2.5-h exercise plus language stimulation session, and supervised one 1.5-2-h community activity session per week for 10 weeks per semester. A family member supervised 10 weekly exercise sessions.

\subsection{Physical fitness}

The physical fitness intervention that provided the context for the language and memory stimulation activities consisted of a treadmill and stationary bicycle workout, strength training on five machines, and flexibility and balance exercises. Details and outcomes have been described elsewhere (Arkin, 1999, in press). 


\subsection{Community activity sessions}

Sessions alternated between supervised volunteer service at community agencies and cultural or recreational activities (Arkin, 2001). Students were instructed to incorporate 20 min of walking into the community activity sessions, to bring the frequency of aerobic activity to the usually recommended three times per week.

\subsection{Cognitive-linguistic activities}

The portfolio of language activities provided practice in the important cognitive operations identified by Orange and Purves (1996) as relevant to conversational performance. Each activity and the cognitive process/es it tapped into are listed below. Students were instructed and repeatedly reminded to use these exercises as a launchpad for dialogue between them and their partners, not simply to record a first response and quickly move on. Each activity was labeled either "during" or "rest" to indicate whether it was to be administered during an aerobic activity or during a rest period. Tasks requiring concentration or deep processing were reserved for rest periods. All activities required participants to maintain attention to the task and to perform some form of deep processing (Craik \& Lockhart, 1972) in response to a presented stimulus and to produce verbal responses. A complete list, brief description, and examples of language activities used in the Elder Rehab program are presented in Table 2. Nine or 10 were used during any given semester. Language session report booklets containing participant responses to the various activities were turned in weekly by the students. Record cards containing aerobic and strength training achievements were also completed for each session.

\section{Results}

The effects of the interventions on the four participants' performance on previously listed discourse outcome measures are reported below.

\subsection{Topic comment to total utterance (TC/U) ratio}

Because our interest was in increasing appropriate and on-topic verbal utterances, the chief outcome measure was a ratio of topic comments to total utterances. These data are presented in Fig. 1. Most noteworthy is that two of the four (S1 and S4) participants improved their ratios from baseline to year 4. S1's improvement was modest and consistent, except for a leveling off between years 3 and 4. S4's was erratic, with substantial dips in years 2 and 3 and a dramatic increase in year 4. The two non-improvers (S2 and S3) also showed declines in their second and third years, but S2 again showed improvement in her fourth year. 
Table 2

Language activities used in the Elder Rehab program

Picture description

Car bingo

Object description

Story recall with quiz
Requires attention, visual scanning, naming, narrative discourse production, and processing of literal and interpretive concepts in the picture (e.g., in the Grocery store picture task, a literal concept is "a child spilling eggs" and an interpretive concept is "no one is paying attention to the child"). Advantages of picture description tasks for persons with dementia are that this does not involve memory and concepts missed can be pointed out by directing the participants' attention to the details or contextual cues in the picture. The program's use of this activity differed from the use of picture description as an assessment instrument, when only non-specific cues are given. This activity typically took place at the beginning of the session. A Norman Rockwell was presented. Students would prompt: "Tell me what you see in that picture-what's going on?" After recording the free response, students asked questions (from a prepared list in a resource manual) designed to focus attention on details and relationships and to elicit inferences from pictorial cues

Requires orientation, attention, reading words and short phrases, visuospatial scanning (to search for objects), and procedural memory for what a "bingo" activity involves. This activity occurred during the car ride to and from the intervention site. A large bingo-type card was prepared, each square containing the name of an object that might be seen from a car window (e.g., red pickup truck, driver wearing a hat, dead animal, school bus). Participants were challenged to look for one or more items at a time during a given trip, depending on their ability to focus on more than one item at a time. The date on which an item was observed was written on the card's appropriate square

Utilizes lexical and semantic memory and requires an individual to generate meaningful attributes of a common object. Three objects (lemon, pencil, toothbrush) were presented in order and participants were asked to describe them. Based on the spontaneous response, prompt questions were asked to elicit additional information

This activity employs a fixed interval type of spaced retrieval (Camp et al., 1995) and challenges participants' explicit and episodic memory. The format is similar to that used in a series of successful autobiographical memory training studies with Alzheimer patients (Arkin, 1992, 1997, 1998, 2000). Students read a brief story containing six-seven facts and asked partners to re-tell the story immediately after presentation. Students then re-read story, posing a question about each fact after it was stated, pausing for the partner to answer, if able, then giving the correct answer. Students then repeated all six questions and solicited their partner's answers, giving the correct one if s/ he failed to answer correctly. The partner was then asked to re-tell the story. When five out of six questions were answered correctly and the partner spontaneously recalled four major facts about the story, a new story was introduced for the following session. Topics of stories were adult in content and emotionally charged (see Appendix $\mathrm{C}$ for an example) 
Table 2 (Continued)

Category fluency- Utilizes the relatively preserved implicit memory systems of AD patients naming-quiz

Opinion and advice questions

Pros and cons

Problem solving

A my name is ... game
(Bäckman, 1992; Camp et al., 1995) and fosters production of non-studied novel exemplars through the process of spreading activation (Bayles \& Kaszniak, 1987; Collins \& Loftus, 1975). A 60-s category fluency test was administered (e.g., things people wear) 18-20 times in a given semester, typically before and after each exercise session. A master (baseline) list of all the different exemplars ever named by each participant during those tests was compiled. The subsequent semester, participants were presented with a 40- to 50 -item study task at the start of their exercise session. Pictures of items from the subject category were alternated with questions about the same topic (e.g., What might a woman wear to bed instead of pajamas?). Correct answers were supplied. At the end of the exercise session, the category fluency test was given again. Lists produced following exposure to study tasks were analyzed for (a) words never named at baseline, but that were on the study task-evidence for implicit learning; and (b) novel words, i.e., words never named at baseline and that were not on the study task-evidence of spreading activation. Results obtained for the clothing category on this task are published elsewhere (Arkin, Rose, \& Hopper, 2000)

Requires participants to use logical thinking, reasoning, and moral judgment. A situation involving a moral issue or personal values is presented to participants and their opinion solicited. Probe questions were asked after recording an initial, spontaneous response. Controversial adult topics and dilemmas were presented. For example, "Would you help a terminally ill friend hide pills he was accumulating in order to commit suicide?" This activity was successfully used in a geropsychiatric hospital in Germany to counteract loss of social roles and functions that accompanies institutionalization (Muller, 1993)

Enables participants to practice reasoning skills. Participants were given a series of topics or objects and were asked to tell what was good and bad about each one. Students used topics and responses as a springboard for conversation, sharing their opinions during the dialogue. For example, retirement, cell phones, etc.

Focuses on participants' critical thinking and reasoning skills. One of a series of picture cards developed for use with adults with disabilities (Pitti \& Meier, 1992) was presented at each session. Each card depicts a daily living situation in which a problematic or dangerous element is present. For example, a depicted situation might include someone reaching into an oven with bare hands

Provides practice in generative naming, set shifting, and executive function skills. Students read the framework phrase and asked participants to produce an appropriate word (man's/woman's name, place name, etc.) beginning with the target letter for each blank (A my name is — and my (wife's) name is — and we come from — and we're going downtown to buy — B B my name is —, etc.). Higher functioning participants were asked to advance through the alphabet with each word produced (e.g., A: Alice, B: Bob, C: Chicago, etc.) 
Table 2 (Continued)

Similarities

Proverb completion and interpretation

Famous names

Word association

Sentence completion

tes creative thinking and linguistic expression through completion of sentences. Students presented a series of sentence stems and asked participants to complete the sentences in their own words. Students offered their own responses and engaged their partner in dialogue. For example, If I had a million dollars, I _ _ I'm afraid of —

During the first year of treatment, S1 and S4 improved, S2 stayed the same, and S3 declined on TC/U ratio.

\subsection{Different noun to total noun (DN/TN) ratio}

DN/TN ratios were calculated to yield a type-token ratio indicative of the richness of a participant's discourse and vocabulary. The long-term outcome on 


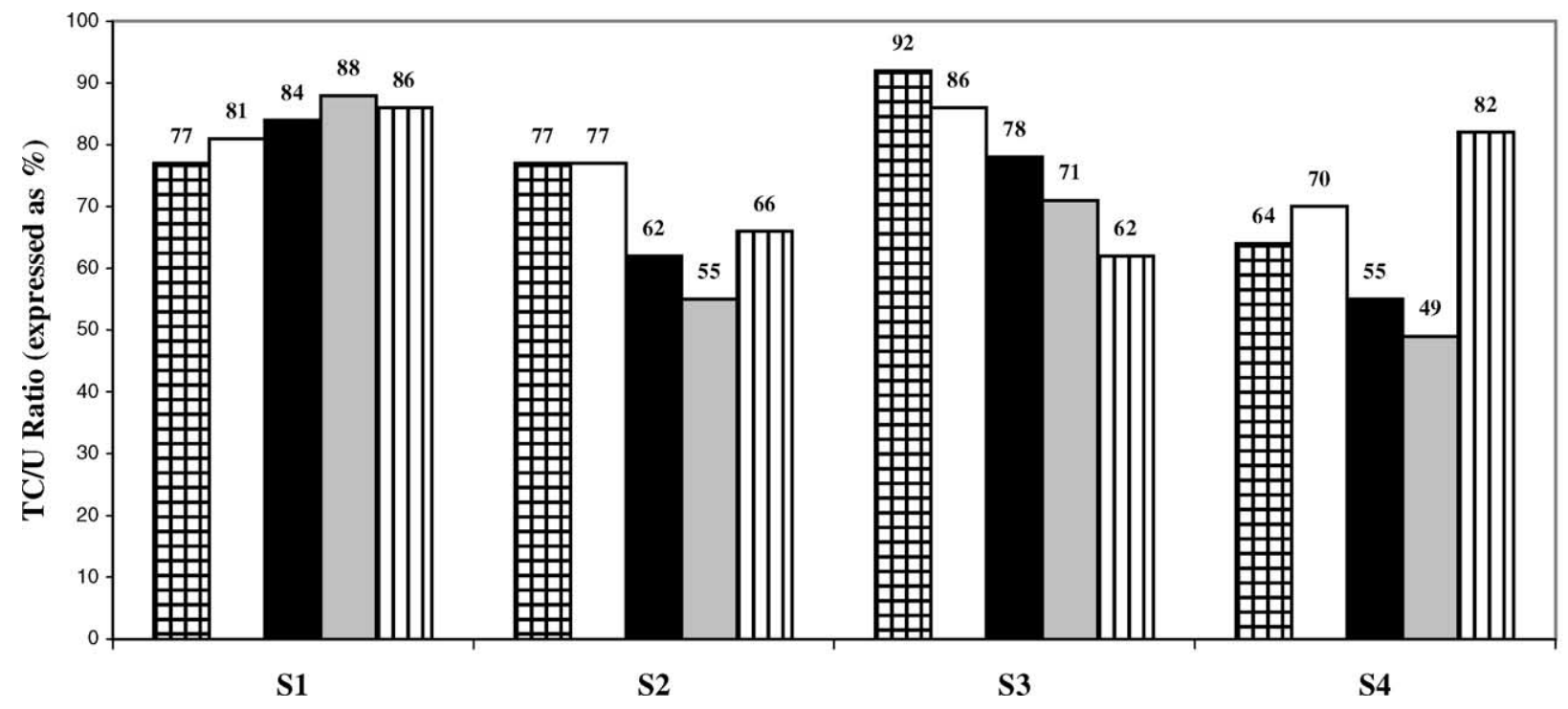

Fig. 1. Topic comment to total utterance ratio. 
this measure was positive, with all four participants showing changes of 5 percentage points or fewer from their baseline scores to year $4-2$ in the positive direction, 2 in the negative direction. Between-year scores showed greater fluctuations for two of the participants: S3's performance peaked, then dipped in years 2 and 3 before reaching and exceeding her baseline score; S1 registered a temporary decline in year 3 , but came within 3 percentage points of his baseline score in year 4 (Fig. 2).

\subsection{Vague noun to total noun (VN/TN) ratios}

The use of vague nouns instead of specific nouns is indicative of the empty speech and word retrieval difficulties associated with an increase in dementia severity. A low percentage of vague nouns to total nouns is a positive outcome on this measure. All four participants had negligible changes from their very low baseline ratios (1-5\%) to year 3. Three of the four had year 4 ratios of $0-3 \%$. S2, the only moderate stage $\mathrm{AD}$ patient in the group, had a $10 \%$ ratio in year 4 , compared to her baseline ratio of $5 \%$, not a big increase (Fig. 3).

\subsection{Negative utterance to total utterance ratio}

Utterances classified as negative in our coding system consisted of repetitions (TCRs), confabulations (TC/CONs), factually erroneous statements (TCEs), offtopic statements (OT), incomplete thoughts (ITHs), and incoherent or "meaning unclear" (MU) statements, perseverations (PERSEV), erroneous response to questions (EQ), and topic comments with anomia (TC/ANOM). On the ratio of negative to total utterances, S1 showed a decrease; with S2 and S4 maintaining ( 2 percentage points up or down) this ratio from baseline to year 4 (Table 3 ). However, S2 and S4 showed an increase in negative utterances in year 2 before

Table 3

Individual ratios of negative utterances to total utterances by testing occasion

\begin{tabular}{llllll}
\hline & Baseline & Year 1 & Year 2 & Year 3 & Year 4 \\
\hline S1 & $13.8 \%$ & $10.8 \%$ & $10.4 \%$ & $12 \%$ & $3.8 \%$ \\
& $9 / 65$ & $8 / 74$ & $10 / 96$ & $9 / 75$ & $3 / 77$ \\
S2 & $12.3 \%$ & $7.5 \%$ & $20.8 \%$ & $19 \%$ & $11.3 \%$ \\
& $25 / 202$ & $29 / 384$ & $72 / 346$ & $61 / 321$ & $26 / 231$ \\
S3 & $6.9 \%$ & $7.7 \%$ & $8.7 \%$ & $11.9 \%$ & $15.8 \%$ \\
& $20 / 287$ & $17 / 221$ & $23 / 263$ & $30 / 251$ & $27 / 170$ \\
S4 & $8.7 \%$ & $10.2 \%$ & $27 \%$ & $12.3 \%$ & $10.7 \%$ \\
& $19 / 219$ & $37 / 362$ & $79 / 291$ & $54 / 438$ & $51 / 474$ \\
Total & $9.4 \%$ & $8.7 \%$ & $18.4 \%$ & $14 \%$ & $11.2 \%$ \\
& $73 / 773$ & $91 / 1041$ & $184 / 996$ & $154 / 1085$ & $107 / 952$ \\
\hline
\end{tabular}




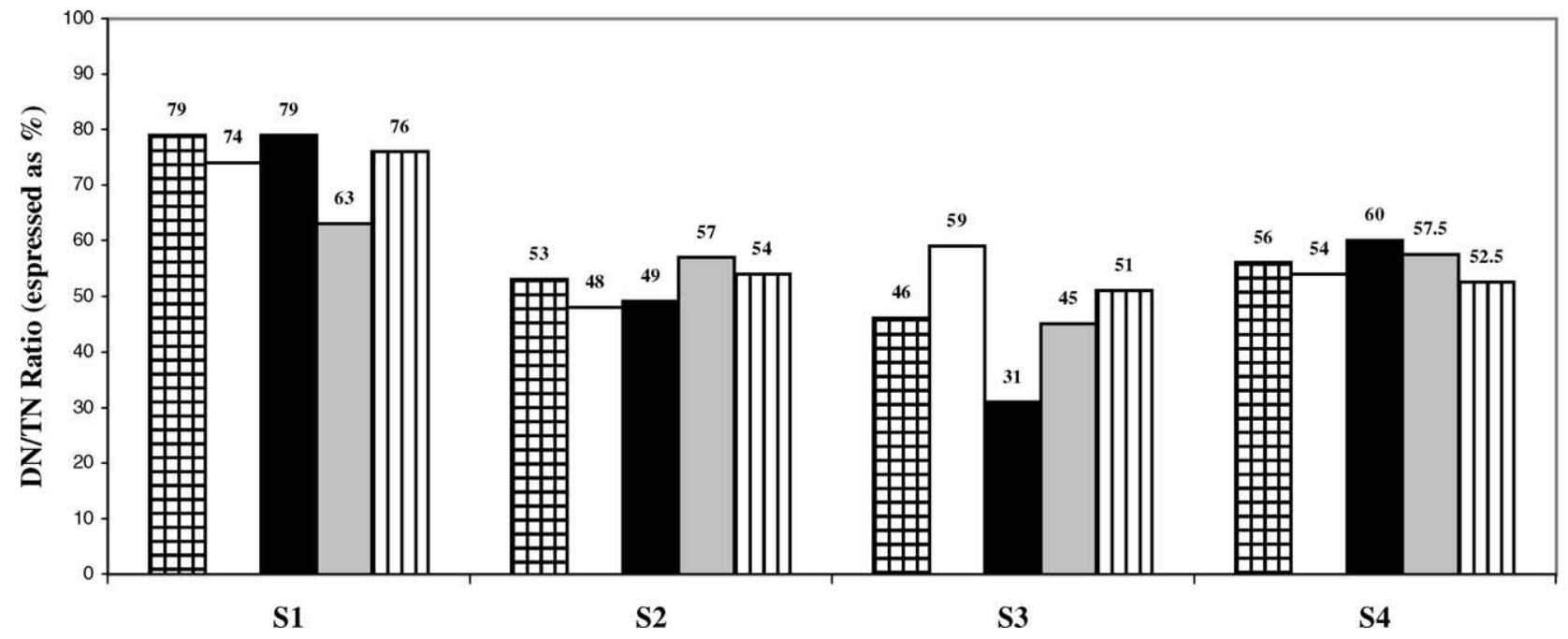

\begin{tabular}{|l|}
\hline QBL \\
QYR 1 \\
EYR 2 \\
QYR 3 \\
QYR 4 \\
\hline
\end{tabular}

Fig. 2. Different noun to total noun ratio. 


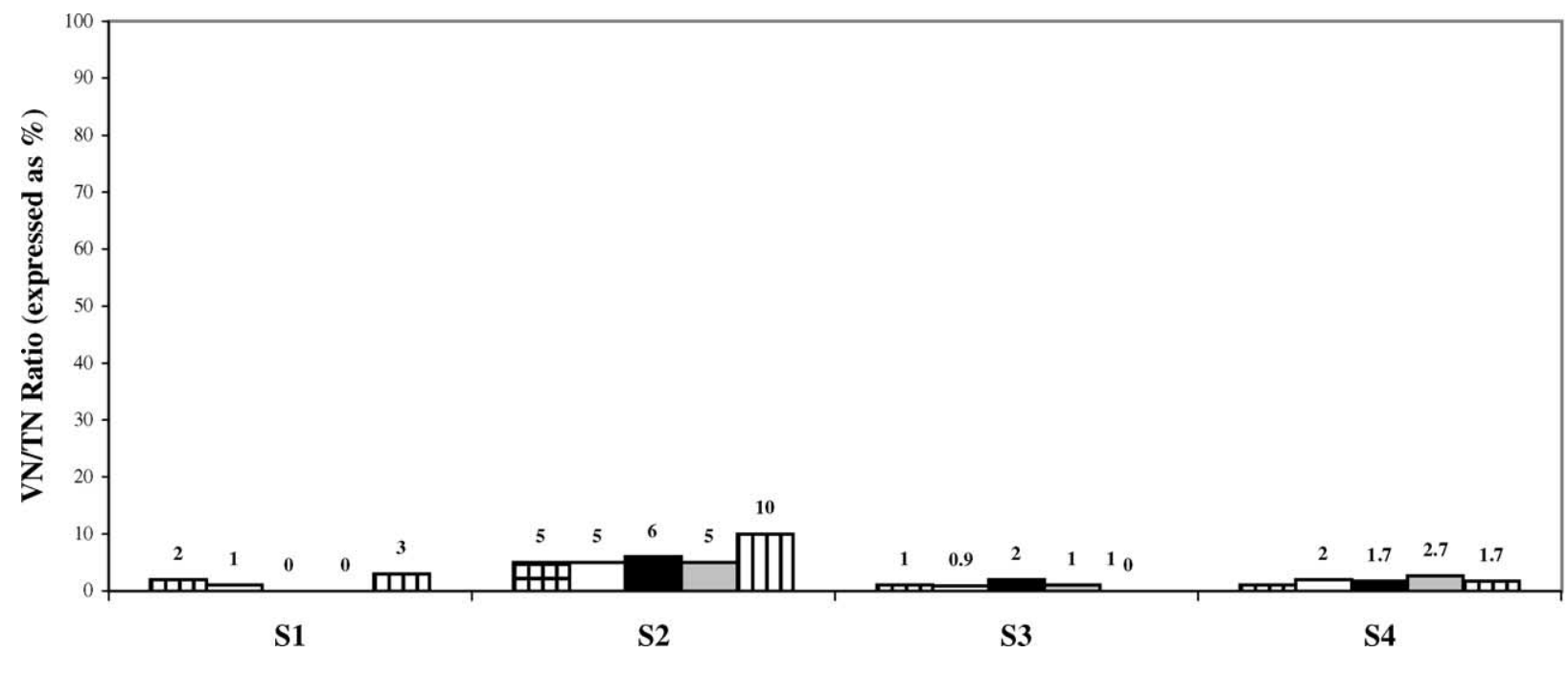

\begin{tabular}{|l|}
\hline DBL \\
QYR 1 \\
GYR 2 \\
GYR 3 \\
GYR 4 \\
\hline
\end{tabular}

Fig. 3. Vague noun to total noun ratio. 
returning to near-baseline levels. Both these participants presented with significant increases in off-topic comments (OT), these being the most frequent negative utterance in their discourse. S3 showed a steady increase, mirroring her steadily declining performance on the $\mathrm{TC} / \mathrm{U}$ ratio.

Analysis of specific types of negative utterances relative to total negative utterances produced by the group of four revealed that at every test time except year 2, topic comment repetitions (TCRs) accounted for the largest percentage of negative utterances. At year 2, off-topic comments were the predominant type. Four types of negative utterances-topic comment repetitions, incomplete thoughts, "meaning unclear" statements, and erroneous topic comments were features seen in each participant's discourse at one or more test times. TCRs were recorded consistently in each participant's discourse at every single test time. Confabulations were observed consistently over time only in the discourse of S4 with the exception of baseline testing when S2 made two confabulatory statements.

\subsection{Proverb interpretation performance}

All four participants improved or equaled their baseline performance at year 4 , with only small fluctuations between years (see Fig. 4). The three mild stage participants all scored 25 or above out of a possible 30 points at baseline. S2 improved her baseline score of 17 to a peak of 22 at year 3, but dropped back to 18 in year 4. These data provide evidence of preserved abstract reasoning ability by all four participants, even as dementia severity increased (Figs. 5 and 6 for change in MMSE and ABCD scores over time).

\subsection{Grocery store picture description}

Performance on this task showed more inter- and intra-respondent fluctuations than on any of the others. Three out of four performed best in year 3, substantially exceeding their baseline scores (Fig. 7). S4 essentially matched her baseline score (two-point difference) in that year.

Scores for the three best performers in year 3 had substantially lower scores in year 4; only S2 showed a final post-test improvement over baseline. S4's fourth year testing session inadvertently skipped picture description. Interestingly, on all testing occasions, all four participants' scores exceeded the mean score of non-demented elderly individuals in the standardization sample of the ADP $($ mean $=21.6$, S.D. $=8.8$; Helm-Estabrooks, 1992).

\subsection{Standardized test results}

First year outcomes on all of the standardized tests have been reported elsewhere (Arkin, 2001). Baseline and four annual MMSE and ABCD scores 


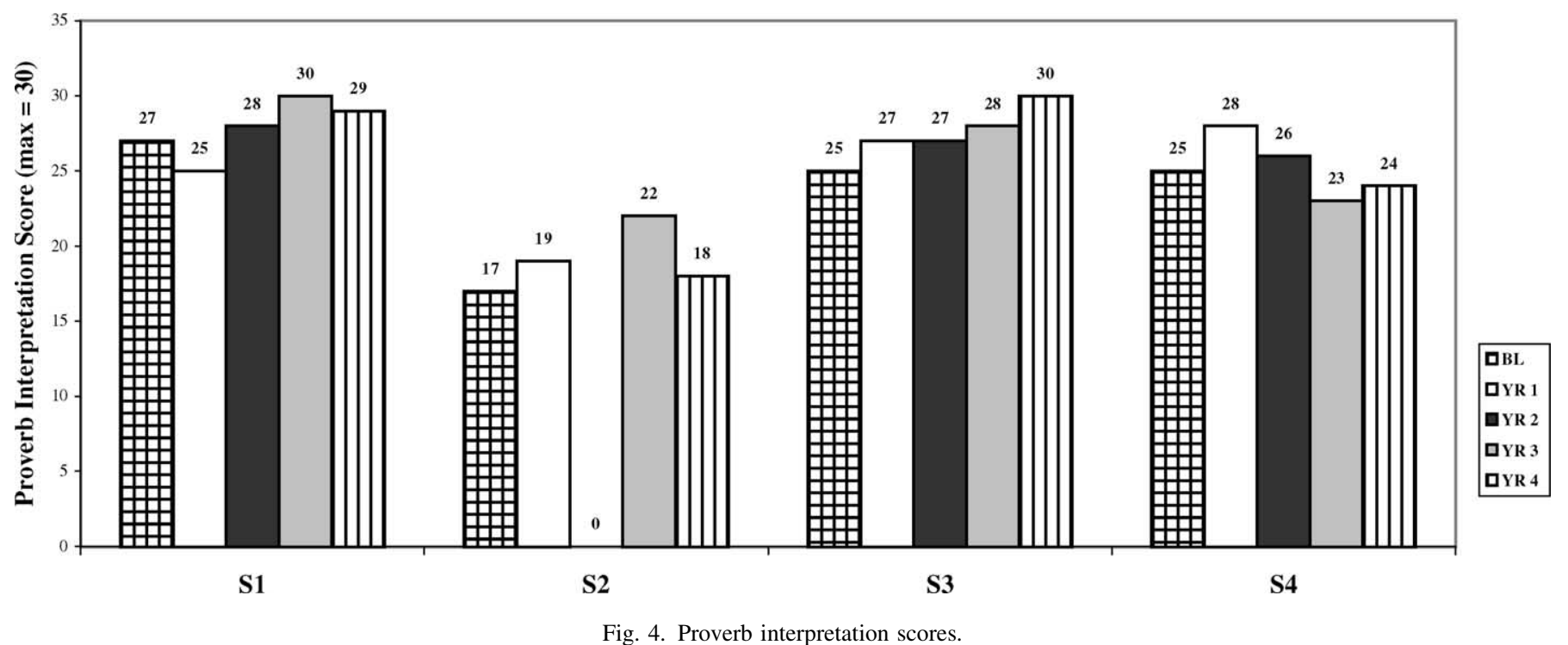

Fig. 4. Proverb interpretation scores. 




Fig. 5. MMSE score changes over 4 years. 






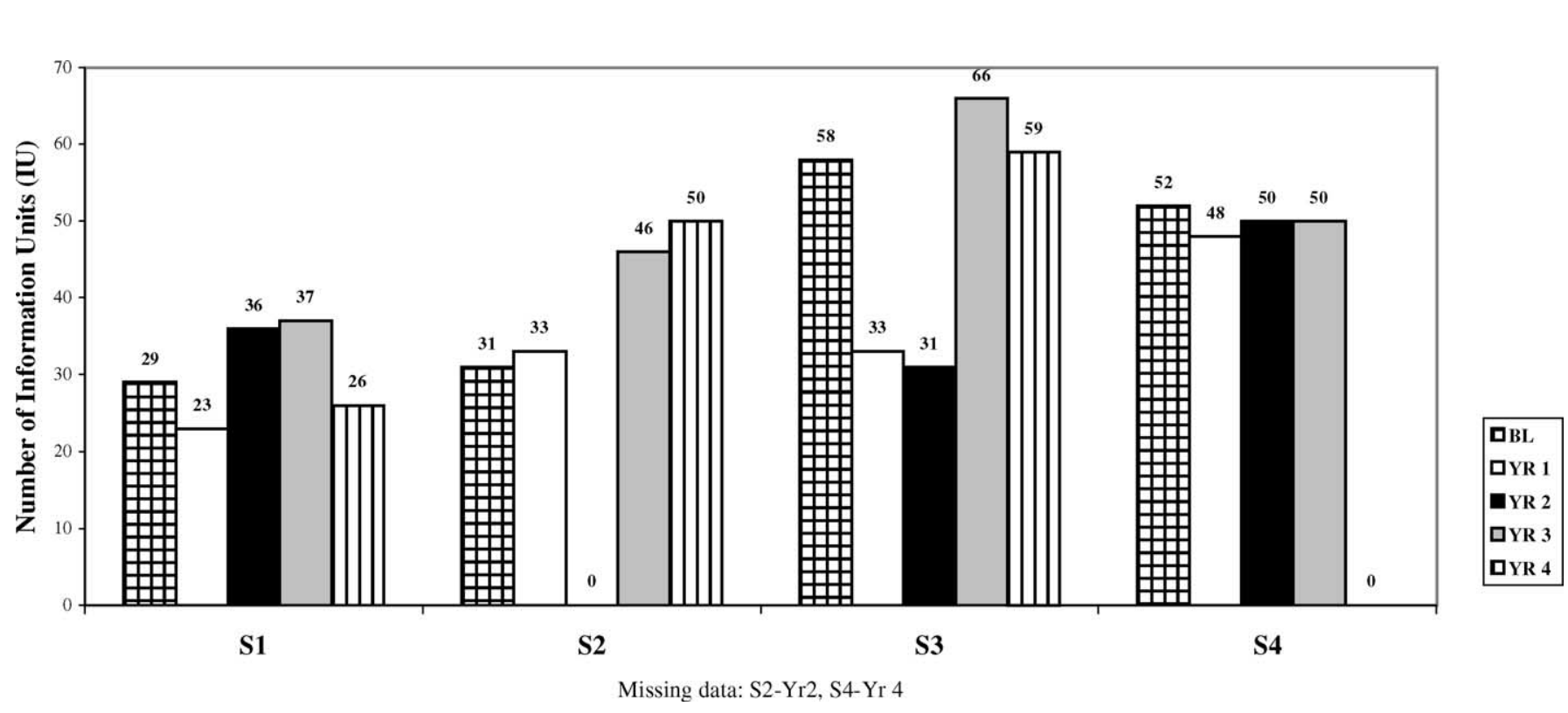

Fig. 7. Grocery store picture description performance. 
for the four veterans are presented in Figs. 5 and 6. Final fitness outcome data are in press (Arkin, in press). Final outcome data and comparisons between the Elder Rehab participants and an untreated matched sample from the CERAD study are being reported in an article that is in progress by the second author. See also the outcomes section on the Elder Rehab website: www.u.arizona.edu/ sarkin/ elderrehab.html.

\section{Discussion}

\subsection{Discourse outcomes}

The data from our four AD participants provide preliminary evidence that long-term cognitive-linguistic interventions can maintain or improve aspects of language performance in very different individuals with a progressive dementia. While the language and communicative impairments associated with various stages of dementia are well documented, most of these studies are cross-sectional and compare the performance of AD patients with normal controls or with other aphasic groups (Bayles, Tomoeda, \& Trosset, 1992; Giles, Patterson, \& Hodges, 1996; Smith, Chenery, \& Murdoch, 1989; Tomoeda, Bayles, Trosset, Azuma, \& McGeagh, 1996). In existing longitudinal studies, investigators have tracked the progression of untreated individuals (e.g., Morris et al., 1993; Ripich, Fritsch, Ziol, \& Durand, 2000; Tomoeda \& Bayles, 1993). The few studies that report positive effects from direct interventions (Camp et al., 1995; Clare et al., 2000; Hopper, Bayles, \& Tomoeda, 1998; Mahendra, 2001; Quayhagen, Quayhagen, Corbeil, Roth, \& Rodgers, 1995) are short-term.

It is clear that our four participants responded differently to these interventions. Each of them challenged, in some way, oft-stated characterizations of the language of Alzheimer's as increasingly empty, vague, and concrete as dementia progresses (Hier, Hagenlocker, \& Schindler, 1985; Nicholas, Obler, Albert, \& Helm-Estabrooks, 1985). Each of them demonstrated an idiosyncratic communication style at baseline and maintained that style for the next 4 years, despite ups and downs on specific measures.

\subsection{Proverb interpretation}

An exciting finding was that all four participants improved or equaled their performance on proverb interpretation from baseline to year 4. Given the sensitivity of a PI task to declines in abstract verbal reasoning (Van Lancker, 1990) and figurative language processing, we elected to use a proverb interpretation task as one of our discourse outcome measures. Chapman et al. (1997) compared persons with fluent aphasia, persons with $\mathrm{AD}$ and healthy elders on their ability to interpret familiar and unfamiliar proverbs. They found 
that persons with AD performed well on interpretation of familiar proverbs but had difficulty with unfamiliar proverbs. Van Lancker (1990) suggests that familiar proverbs are stored in semantic memory as a single unit of meaning and are likely retrieved like lexical items. This may make them easier to interpret than unfamiliar proverbs, which require more inferencing. Our proverb interpretation task consisted of familiar proverbs, which may explain our participants' success in interpreting them over a 4-year period. There are two other possible explanations. First, semantic knowledge is not as degraded in mild dementia as in moderate and late stage dementia and this might facilitate performance on a PI task (see Bayles \& Kim, 2003, this volume, for a more extensive discussion). Second, these participants were receiving a specific proverb interpretation and proverb completion intervention as part of the language activities. It is possible that repeated stimulation of figurative language concepts and abstract verbal reasoning during active completion of proverb stems and generation of their meanings could have generalized to performance on the PI task.

\subsection{Picture description}

Performance of $\mathrm{AD}$ patients on picture description has been investigated extensively in cross-sectional studies (Bayles et al., 1992; Giles et al., 1996; Hier et al., 1985; Tomoeda et al., 1996). All these studies report an association between increased dementia severity and decreased production of information units. While our participants did decline in mental status during the 4 years (Figs. 5 and 6), the three who were mild stage at baseline remained only mildly demented 4 years later. Counter intuitively, S2, the only moderate stage patient at baseline declined only 2 points on the MMSE in the 4 years, and was the only participant to show a robust improvement on picture description over time. The others produced virtually the same number of information units as they did at baseline (one-, two-, or three-point differences) whereas, over a 4-year period, a decline would have been expected.

Picture description is the only task used here about which there is published longitudinal data on untreated AD patients (Tomoeda \& Bayles, 1993). The improved or maintained performance by our four participants who received the Elder Rehab interventions stands in contrast to the progressive decline in information units on a picture description task produced by untreated AD patients over a 5-year period (Tomoeda \& Bayles, 1993). The three patients in their study started with baseline MMSE scores comparable to S2, and lower than three of our participants (S1, S3, and S4). It is reasonable to attribute our participants' good performance on this task to repeated practice on picture description tasks during interventions with specific questions asked to direct their attention to missed details and interpretive concepts. This may have enabled them to internalize strategies such as scanning the picture carefully, and directing attention to literal and interpretive concepts. 


\subsection{Clinical implications}

These data suggest that SLPs need to rethink, redefine and reclaim the spectrum of clinical services that they are qualified to provide to dementia patients. SLPs need to look beyond just providing dysphagia services to conducting cognitive screenings and assessments to determine profiles of spared and impaired abilities, and then structuring interventions that engage individuals' spared abilities. Further, to ensure that $\mathrm{AD}$ patients receive the services they need despite reimbursement constraints, SLPs must think creatively about indirect interventions, that is, working with caregivers (Hopper, 2001), students, and volunteers in administering interventions as described in this article. SLPs can seek to establish partnerships with universities and local speech pathology training programs and offer undergraduate and graduate students clinical training opportunities, thus providing an inexpensive means for delivering individual and group interventions for dementia patients.

Another overlooked opportunity is systematic collaboration with activity directors at long-term care and daycare settings to organize group cognitive stimulation activities to promote social interaction and maintenance of language function. Further, SLPs' understanding of variables that facilitate learning in dementia patients should be shared with other colleagues via regular in-service training in long-term care and daycare settings.

\subsection{Future directions}

Eventually, the various components of this multi-component intervention need to be considered separately, so that it becomes possible to assess the effects of each component as well as their additive effects. Comparison with a no-treatment control group also needs to be made. These preliminary data call for replication on larger groups of individuals with $\mathrm{AD}$, as well as those with varying mental status levels at baseline. Additionally, given the growing number of ethnically diverse elders with dementia, recruiting participants from different cultural groups is essential to a more complete understanding of parameters that affect treatment efficacy and effectiveness. Also, because little is known about how results of longitudinal interventions differ by treatment etiology, inclusion of participant groups with varying etiologies of dementia (e.g., Pick's disease, multi-infarct dementia, AIDS dementia complex) in intervention studies is important.

\section{Acknowledgments}

This research was made possible by a Mentored Research Scientist Development (KO1) award to the second author from the National institute on Aging. Project Title-AD Rehab by Students: Effects on Functioning and Decline. The authors gratefully acknowledge the efforts of Audrey Holland, Nancy Helm-Estabrooks, and Sandra Chapman during various stages of this project. 


\section{Appendix A. BASICS model}

Adapted from Ronch (1987) and Ryden and Feldt (1992)

\begin{tabular}{ll}
\hline Need addressed & Outcome of addressing specific need \\
\hline B-Biological & $\begin{array}{l}\text { Promotes sense of security/safety } \\
\text { A-Activities of } \\
\text { daily living }\end{array}$ \\
S-Societal & $\begin{array}{l}\text { Promotes sense of independence and control over } \\
\text { Fosters a sense of unique identity and self-worth; } \\
\text { meaningful participation as per individual's view }\end{array}$ \\
I-Interpersonal & $\begin{array}{l}\text { Provides opportunity for social role expression and } \\
\text { confidence; to care for others and be cared about }\end{array}$ \\
E-Creative & $\begin{array}{l}\text { Encourages use of spared talents/skills and supports } \\
\text { independent activity; helps identify activities that } \\
\text { provide optimal stimulation } \\
\text { Encourages hopefulness, self-actualization, and need } \\
\text { for self-fulfillment (doing your best; being all you } \\
\text { can be) despite loss of self due to dementia }\end{array}$ \\
\hline
\end{tabular}

\section{Appendix B}

Proverb interpretation scoring system used by Chapman et al. (1997). Modified from Delis et al. (1984)

\begin{tabular}{ll}
\hline 6 & Correct abstract response \\
5 & Partial abstract response \\
4 & Incomplete, partial abstract response \\
3 & Correct concrete response \\
2 & Partial concrete response \\
1 & Incomplete, partial concrete response \\
$0-\mathrm{A}$ & Incorrect abstract response \\
$0-\mathrm{C}$ & Incorrect concrete response \\
$0-\mathrm{NR}$ & Incorrect no response \\
\hline
\end{tabular}

\section{Appendix C. Story recall with quiz (example)}

\section{POOR PUPPY}

A cocker spaniel puppy that is usually kept in the basement got into the living room when the owner was at work. When the puppy's owner got home, she found a wet spot on the carpet. She spanked the puppy with a newspaper. Then she noticed water dripping from the ceiling right over the wet spot on the carpet. She apologized to the puppy and gave him a biscuit. 
1. This story is about a cocker spaniel puppy. What kind of puppy is the story about? (cocker spaniel).

2. The cocker spaniel puppy is usually kept in the basement. Where is the puppy usually kept? (basement).

3. One day, the puppy got into the living room when the owner was at work. Where did the puppy go while the owner was at work? _ (into the living room).

4. When the puppy's owner got home, she found a wet spot on the carpet. What did the puppy's owner find on the carpet when she got home? (a wet spot).

5. She spanked the puppy with a newspaper. What did the owner do to the puppy? (spanked him with a newspaper).

6. Then she noticed water dripping from the ceiling right over the wet spot on the newspaper.

7. What really caused the wet spot on the carpet that the puppy was blamed for? (water dripping from the ceiling).

\section{Appendix D. Continuing education}

1. SLPs in long-term health care settings most often work with AD patients to provide:
a. assessment and management of communicative difficulties
b. assessment and management of communicative and swallowing difficulties
c. assessment of management of memory difficulties
d. assessment and management of swallowing difficulties
e. assessment and management of memory and swallowing difficulties

2. In this study, authors report data on discourse outcomes of four participants with $\mathrm{AD}$ who were simultaneously receiving:

a. physical exercise and cognitive-linguistic interventions

b. cognitive-linguistic interventions only

c. community activity, exercise, and cognitive-linguistic interventions

d. community activity and cognitive-linguistic interventions

e. physical exercise and community activity

3. One discourse outcome measure on which all four participants described in this article consistently improved or maintained performance over time was:

a. proverb interpretation scores

b. topic comment to total utterance ratio

c. different noun to total noun ratio

d. number of information units on the Grocery store picture description task

e. score obtained on the ABCD 
4. The results of this study provide preliminary evidence to support the effectiveness of a combination of interventions in:

a. maintaining language and communicative function in $\mathrm{AD}$ patients over time

b. maintaining or improving language and communicative function in $\mathrm{AD}$ patients over time

c. maintaining or improving global cognitive status in $\mathrm{AD}$ patients over time

d. maintaining or improving physical fitness of $\mathrm{AD}$ patients over time

e. improving language and communicative function in $\mathrm{AD}$ patients over time

5. SLPs can ensure that AD patients receive adequate services by thinking creatively about participation of:

a. activities directors

b. caregivers, students, and volunteers

c. physicians and nurse practitioners

d. nurse practitioners and dietitians

e. activities directors, caregivers, students, and volunteers

\section{References}

Arkin, S. (1992). Audio-assisted memory training with early Alzheimer's patients: Two single subject experiments. Clinical Gerontologist, 12, 77-95.

Arkin, S. (1995). Volunteers in partnership: A rehabilitation program for Alzheimer's patients. In National Center for Neurogenic Communication Disorders (Producer), Telerounds. Tucson, AZ.

Arkin, S. (1996). Volunteers in partnership: An Alzheimer's rehabilitation program delivered by students. American Journal of Alzheimer's Disease, 11, 12-22.

Arkin, S. (1997). Alzheimer memory training: Quiz beats repetition, especially for more impaired. American Journal of Alzheimer's Disease, 12, 147-158.

Arkin, S. (1998). Alzheimer memory training: Positive results replicated. American Journal of Alzheimer's Disease, 13, 102-104.

Arkin, S. (1999). Elder rehab: A student-supervised exercise program for Alzheimer's patients. The Gerontologist, 39, 729-735.

Arkin, S. (2000). Alzheimer memory training: Students replicate learning successes. American Journal of Alzheimer's Disease, 15, 152-162.

Arkin, S. (2001). Alzheimer rehabilitation by students: Interventions and outcomes. Neuropsychological Rehabilitation, 11(3-4), 273-317.

Arkin, S. (in press). Student-led exercise sessions yield significant fitness gains for Alzheimer's patients. American Journal of Alzheimer's Disease.

Arkin, S., \& Mahendra, N. (2001a). Discourse analysis of Alzheimer's patients before and after interventions: Methodology and outcomes. Aphasiology, 15(6), 533-569.

Arkin, S., \& Mahendra, N. (2001b). Insight in Alzheimer patients: Results of a longitudinal study using three assessment methods. American Journal of Alzheimer's Disease, 16(4), 211-224.

Arkin, S. A., \& Mahendra, N. (in press). Geriatric depression scale as dementia insight indicator: Three case examples. Clinical Gerontologist, 26(3-4).

Arkin, S., Rose, C., \& Hopper, T. (2000). Implicit and explicit learning gains in Alzheimer's patients: Effects of naming and information retrieval training. Aphasiology, 14, 723-742. 
Bäckman, L. (1992). Memory training and memory improvement in Alzheimer's disease. Acta Neurologica Scandinavica, 84(Suppl. 139), 84-89.

Bayles, K. A. (2001). Understanding the neuropsychological syndrome of dementia. Seminars in Speech \& Language, 22(4), 251-273.

Bayles, K. A., \& Kaszniak, A. W. (1987). Communication and cognition in normal aging and dementia. Boston: College Hill.

Bayles, K. A., \& Kim, E. S. (2003). Improving the functioning of individuals with Alzheimer's disease: Emergence of behavioral interventions. Clinics in Communication Disorders.

Bayles, K. A., \& Tomoeda, C. (1991). Arizona battery for communication disorders of dementia $(A B C D)$. Tucson, AZ: Canyonlands Publishing.

Bayles, K. A., Tomoeda, C. K., \& Trosset, M. W. (1992). Relation of linguistic communication abilities of Alzheimer's patients to stage of disease. Brain and Language, 42, 454-472.

Berg, L. (1988). Clinical dementia rating (CDR). Psychopharmacology Bulletin, 24, 637-639.

Camp, C. J., Foss, J. W., O'Hanlon, A. M., \& Stevens, A. B. (1995). Memory interventions for persons with dementia. Applied Cognitive Psychology, 9, 374.1-374.18.

Chapman, S., Ulatowskah, H., Franklin, L., Shobe, A., Thompson, J., \& McIntire, D. (1997). Proverb interpretation in fluent aphasia and Alzheimers disease: Implications beyond abstract thinking. Aphasiology, 11(4/5), 337-350.

Clare, L., Wilson, B. A., Carter, G., Breen, K., Gosses, A., \& Hodges, J. R. (2000). Intervening with everyday memory problems in dementia of the Alzheimer type: An errorless learning approach. Journal of Clinical and Experimental Neuropsychology, 22, 132-146.

Clark, L. (1995). Interventions for persons with Alzheimer's disease: Strategies for maintaining and enhancing communicative success. Topics in Language Disorders, 15, 47-65.

Clark, L., \& Witte, K. (1991). In R. Lubinski (Ed.), Dementia and communication (pp. 238-256). Philadelphia: B.C. Decker, Inc.

Collins, A. M., \& Loftus, E. F. (1975). A spreading-activation theory of semantic processing. Psychological Review, 82, 407-428.

Craik, F. I. M., \& Lockhart, R. S. (1972). Levels of processing: A framework for memory research. Journal of Verbal Learning and Verbal Behavior, 11, 671-684.

Delis, D. C., Kramer, J., \& Kaplan, E. (1984). The California proverb test. Unpublished protocol.

Evans, D. A. (1990). Estimated prevalence of Alzheimer's disease in the United Sates. Milbank $Q$, $68,267-289$.

Folstein, M., Folstein, S., \& McHugh, P. (1975). Mini-mental state: A practical method for grading the cognitive state of patients. Journal of Psychiatric Research, 12, 189-198.

Giles, E., Patterson, K., \& Hodges, J. R. (1996). Performance on the Boston cookie theft picture description task in patients with early dementia of the Alzheimer's type: Missing information. Aphasiology, 10(4), 395-408.

Helm-Estabrooks, N. (1992). Aphasia diagnostic profiles. New York: Riverside Publishing Co.

Hier, D. B., Hagenlocker, K., \& Schindler, A. G. (1985). Language disintegration in dementia: Effects of etiology and severity. Brain and Language, 25, 117-133.

Hirsch, E. D., Kett, J. F., \& Trefil, J. (1988). Dictionary of cultural literacy: What every American needs to know. Boston: Houghton Mifflin.

Hopper, T. (2001). Indirect interventions to facilitate communication in Alzheimer's disease. Seminars in Speech \& Language, 22(4), 305-315.

Hopper, T. L., Bayles, K. A., \& Tomoeda, C. K. (1998). Using toys to stimulate communicative function in individuals with Alzheimer's disease. Journal of Medical Speech Language Pathology, 6, 73-80.

Kaplan, E. F., Goodglass, H., \& Weintraub, S. (1983). The Boston naming test (2nd ed.). Philadelphia: Lea \& Febiger.

Lezak, M. D. (1995). Neuropsychological assessment. New York: Oxford University Press.

Mahendra, N. (2001). Direct interventions for improving the performance of individuals with Alzheimer's disease. Seminars in Speech \& Language, 22(4), 291-304. 
McKhann, G., Drachman, D., Folstein, M., Katzman, R., Price, D., \& Stadlan, E. M. (1984). Clinical diagnosis of Alzheimer's disease. Report of the NINCDS-ADRDA work group under the auspices of the Department of Health and Human Services Task Force on Alzheimer's disease. Neurology, 34, 939-944.

Morris, J. C., Edland, S., Clark, C., Galasko, D., Koss, E., Mohs, R., van Belle, G., Fillenbaum, G., \& Heyman, A. (1993). The consortium to establish a registry for Alzheimer's disease (CEAD). Part IV. Rates of cognitive change in the longitudinal assessment of probable Alzheimer's disease. Neurology, 43, 2457-2465.

Morris, J. C., Heyman, A., Mohs, R. C., Hughes, M. S., van Belle, G., Fillenbaum, G., Mellits, E. D., Clark, C., \& the CERAD investigators. (1989). The consortium to establish a registry for Alzheimer's disease (CERAD). Part I. Clinical and neuropsychological assessment of Alzheimer's disease. Neurology, 39, 1159-1165.

Moss, S., Polignano, E., White, C. L., Minichiello, M., \& Sunderland, T. (2002). Reminiscence group activities and discourse interaction in Alzheimer's disease. Journal of Gerontological Nursing, 36-44.

Muller, A. A. (1993). Ressourcensicherung durch Aktivierung der Ratgeberfunktion des alteren Menschen-Ein neues Konzept in der Gerontoposychiatrie (Maintaining resources by activating the advisory function of the elderly: A new concept in gerontopsychiatry). Zeitschrift fur Gerontopsychologie \& Psychiatrie, 6, 119-125.

Nicholas, M., Obler, L., Albert, M., \& Helm-Estabrooks, N. (1985). Empty speech in Alzheimer's disease and fluent aphasia. Journal of Speech \& Hearing Research, 28, 405-410.

Omnibus Budget Reconciliation Act of 1987. (1987). Public Law \# 100-203, 483.15.

Orange, J. B., \& Purves, B. (1996). Conversational discourse and cognitive impairment: Implications for Alzheimer's disease. Journal of Speech-Language Pathology and Audiology, 20(2), 139-150.

Pitti, M. J., \& Meier, T. (1992). Problem solving picture cards: Daily living situations for adults with disabilities. San Antonio, TX: Psychological Corporation.

Quayhagen, M. P., Quayhagen, M., Corbeil, R. R., Roth, P. A., \& Rodgers, J. A. (1995). A dyadic remediation program for care recipients with dementia. Nursing Research, 44, 153-159.

Ripich, D. N., Fritsch, T., Ziol, E., \& Durand, E. (2000). Compensatory strategies in picture description across severity levels in Alzheimer's disease: A longitudinal study. American Journal of Alzheimer's Disease, 15(4), 217-228.

Ronch, J. L. (1987 July/August). Specialized Alzheimer's units in nursing homes: Pros and cons. American Journal of Alzheimer's Care and Related Disorders \& Research, 2, 10-19.

Shadden, B. B. (1995). The use of discourse analyses and procedures for communication programming in long-term care facilities. Topics in Language Disorders, 15, 75-86.

Smith, S. R., Chenery, H. J., \& Murdoch, B. E. (1989). Semantic abilities in dementia of the Alzheimer type. II. Grammatical semantics. Brain and Language, 36, 533-542.

Stansell, J. (2002). Volunteerism: Contributions by people with dementia. In P. B. Harris (Ed.), The person with Alzheimer's disease: Understanding the experience. Baltimore: Johns Hopkins University Press.

Tomoeda, C. K., \& Bayles, K. A. (1993). Longitudinal effects of Alzheimer disease on discourse production. Alzheimer Disease and Associated Disorders, 7(4), 223-236.

Tomoeda, C. K., Bayles, K. A., Trosset, M. W., Azuma, T., \& McGeagh, A. (1996). Cross-sectional analysis of Alzheimer disease effects on oral discourse in a picture description task. Alzheimer Disease and Associated Disorders, 10(4), 204-215.

Van Lancker, D. (1990). The neurology of proverbs. Behavioral Neurology, 3, 169-187.

Wechsler, D. (1981). Manual for the WAIS-R. San Antonio, TX: Psychological Corporation. 